\title{
CIÊNCIA E TECNOLOGIA NA ESCOLA
}

\section{SCIENCE AND TECHNOLOGY AT SCHOOL}

\author{
CIENCIA Y TECNOLOGÍA EN LA ESCUELA
}

\begin{abstract}
FRANCISCO LUIZ DOS SANTOS
Doutor em Física pela Universidade Federal de Pernambuco (UFPE), professor do Programa de Pós-graduação em Tecnologia e Gestão em Educação a Distância da Universidade Federal Rural de Pernambuco (UFRPE), em cedência à Prefeitura do Recife como Secretário Executivo de Educação.
\end{abstract}

\begin{abstract}
Resumo
A evolução das tecnologias desde a metade da década de noventa impôs às escolas um constante repensar em suas abordagens, sobretudo, as que implicam em aprendizagens mediadas pelos instrumentos computacionais ou mesmo digitais, de grande interesse dos jovens na era digital. $\mathrm{O}$ Recife iniciou um programa avançado de tecnologias nas escolas em 2013, bem como, a instalação de Laboratórios de Ciências em meio a readequação de antigos laboratórios de informática para espaços tecnológicos com dispositivos computacionais móveis. Unindo laboratórios de ciências com os espaços tecnológicos, surgiu o programa de laboratórios para a Escola do Futuro, denominados de Laboratórios de Ciência e Tecnologia. Esses laboratórios contemplam um espaço físico único onde são desenvolvidas atividades relacionadas à quatro Laboratórios convencionais: Ciências, Instrumentação Científica, Robótica e Programação e Espaço Maker. Nestes laboratórios, os próprios estudantes podem resolver problemas que façam sentido para eles, fazer experiências e projetos de vida; os professores podem dar aulas práticas e de demonstração, entre outras atividades possíveis. Os projetos, de escolha dos próprios estudantes, são desenvolvidos a partir da aprendizagem baseada em problemas (PBL), aprendizagem prática do mão na massa (Maker) aliado com abordagem educacional que integra ciências, tecnologia, engenharia, artes e matemática, ou seja, STEAM (Science, Technology, Engineering, Arts and Math) (Thibaut, 2018). Neste artigo, mostraremos a construção conceitual, as instalações e resultados obtidos na fase piloto e na fase de funcionamento dos primeiros Laboratórios de Ciência e Tecnologia.
\end{abstract}

Palavras-chave: Laboratórios de Ciências e Tecnologia. Maker. STEAM. PBL.

\begin{abstract}
The evolution of technologies since the mid-nineties has forced schools to constantly rethink their approaches, especially those involving learning mediated by computational or even digital instruments of great interest to young people in the digital age. Recife started an advanced technology program in schools in 2013, as well as the installation of Science Labs at the time of upgrading old computer labs to technology spaces with mobile computing devices. Joining Science Laboratories with the technological spaces, came the Laboratory Program for the School of the Future, called Science and Technology Laboratories. These laboratories include a unique physical space where activities related to four conventional laboratories are developed: Science, Scientific Instrumentation, Robotics and Programming and Space Maker. In these labs, students themselves can solve problems that make sense to them, experiment and design life; Teachers can give practical
\end{abstract}


SANTOS, Francisco Luiz dos.

"Ciência e Tecnologia na Escola"

and demonstration classes, among other possible activities. The projects are developed using modern STEAM and PBL techniques chosen by the students themselves. In this article, we will show the conceptual construction, installations and results obtained in the pilot phase and in the operational phase of the first Science and Technology Laboratories.

Keyword: Science and Technology Lab. Maker. STEAM. PBL.

\section{Resumen}

La evolución de las tecnologías desde mediados de los noventa ha obligado a las escuelas a repensar constantemente sus enfoques, especialmente aquellos que involucran el aprendizaje mediado por instrumentos computacionales o incluso digitales de gran interés para los jóvenes en la era digital. Recife comenzó un programa de tecnología avanzada en las escuelas en 2013, así como la instalación de Science Labs en medio de la readaptación de antiguos laboratorios de computación para espacios tecnológicos con dispositivos informáticos móviles. Uniéndose a los Laboratorios de Ciencia con los espacios tecnológicos, llegó el Programa de Laboratorio para la Escuela del Futuro, llamado Laboratorios de Ciencia y Tecnología. Estos laboratorios incluyen un espacio físico único donde se desarrollan actividades relacionadas con cuatro laboratorios convencionales: Ciencia, Instrumentación Científica, Robótica y Programación y Space Maker. En estos laboratorios, los propios estudiantes pueden resolver problemas que tengan sentido para ellos, experimentar y diseñar la vida; Los docentes pueden impartir clases prácticas y de demostración, entre otras posibles actividades. Los proyectos se desarrollan utilizando técnicas modernas de STEAM y PBL elegidas por los propios estudiantes. En este artículo, mostraremos la construcción conceptual, las instalaciones y los resultados obtenidos en la fase piloto y en la fase operativa de los primeros Laboratorios de Ciencia y Tecnología.

Palabra clave: Laboratorios de Ciencia y Tecnología. Maker. STEAM. PBL.

RBPG, Brasília, v.15, n. 34, 2019.

Experiências Inovadoras 


\section{INTRODUÇÃO}

Há uma constatação, frequentemente repetida, que o modelo de sala de aula, e as próprias aulas, de hoje, repetem o mesmo do século 19. Várias iniciativas têm sido criadas ou propostas, mas ainda formamos educacionalmente os jovens com um professor falando em frente a dezenas de alunos em um espaço retangular. A vida dos jovens mudou bastante comparada com a de um estudante de dois séculos atrás, principalmente com o acesso a recursos que dão dinâmica quase instantânea à busca e ao processamento das informações (HIGGINS, 2012). Esta nova geração tem conexão global e manuseia melhor essas tecnologias que a maioria dos professores (BARRETT, 2015).

No entanto, dilemas antigos que fazem parte da vida dos adolescentes persistem, mesmo que noutro ambiente de possibilidades, como a frustração comum para quem está em fase frágil de amadurecimento psicológico e de rápido crescimento físico. Tudo isso aliado à alta pressão de cobranças em casa e da sociedade faz o jovem não ver nessa escola, inicialmente desenvolvida para o século 19, o atendimento aos seus anseios e motivações diante dos desafios e possibilidades que os rodeiam (BITTENCOURT, 2019).

Frente a essas dificuldades desmotivadoras, algumas possibilidades podem ser desenvolvidas como novas metodologias, com a chegada da robótica, dos jogos digitais e dos tablets ligados à internet. A Prefeitura do Recife inova com a abertura dos Laboratórios de Ciência e Tecnologia nas escolas da rede pública onde todas essas atividades são integradas às experiências clássicas dos laboratórios de ciência, permitindo que os estudantes tenham um espaço, com coordenação própria e integrada à escola, para a realização de suas ideias e soluções de seus problemas.

O jovem pode trazer seus problemas de casa, da rua e até da escola para trabalhar nas soluções dentro do laboratório. Também pode trabalhar com orientação ou proposta do professor, ou de sua própria inspiração, em problemas ou curiosidades universais.

Além dessas, o laboratório tem como principais atividades: aulas de demonstração dadas pelo professor; projetos para feira do conhecimento ou de ciências; projetos especiais com o desenvolvimento de aplicativos/software ou novos dispositivos com soluções contextualizadas por equipes dos clubes de ciência ou robótica; aulas práticas; projetos com pesquisadores das universidades parceiras servindo de espaço mais adequado da escola para determinadas práticas pedagógicas, diferentes das mais comuns (BLIKSTEIN, 2017). Na seção sobre a arquitetura do Laboratório é apresentado o espaço físico, com área adequada ao desenvolvimento das atividades.

Os estudantes e professores da escola têm o apoio integral de um coordenador de laboratório (normalmente um profissional com perfil para atuar em ciência, pesquisa científica e cultura maker com capacidade acima de um graduado de nível superior) e dois auxiliares (estudantes universitários de iniciação científica - PIBIC, ou tecnológica - PIBIT, ou à docência - PIBID, ou extensão - PIBEX, ou simplesmente estudantes estagiários de curso de nível superior de áreas de ciências ou tecnológicas).

A metodologia adotada está baseada na aprendizagem por problematização (PBL), uso dos espaços makers com ferramentas digitais e tecnológicas, além de recursos tradicionais e a abordagem educacional multi e transdisciplinar, Science, Technology, Engineering, Arts and

RBPG, Brasília, v.15, n. 34, 2019.

Experiências Inovadoras 
Math (STEAM) (Thibaut, 2018). Na problematização, o jovem consegue dar sentido a quase tudo que se apresenta a ele, naturalmente em sua vida ou induzido por alguém, definindo com mais precisão os problemas embutidos nas questões ou temas a partir de perguntas e repostas de vários "porquês" e apontando possíveis soluções. Os espaços makers permite o fazer prático com a descoberta de criatividade aliado ao protagonismo e desenvolvimento de competências socioemocionais. Com STEAM, ele lança mão de soluções baseadas em diversas pesquisas científicas, recursos tecnológicos, das engenharias, de arte e matemática. Com essa linha de atividades pedagógicas contextualizadas, o jovem pratica a sua cidadania e o seu protagonismo, sentindo-se mais útil e empoderado para enfrentar desafios, e desenvolve habilidades importantes para este novo século.

Assim, com a implantação dos laboratórios, é possível ver as crianças praticando as (re) descobertas da ciência com a mão na massa e o desenvolvimento de projetos de suas vidas.

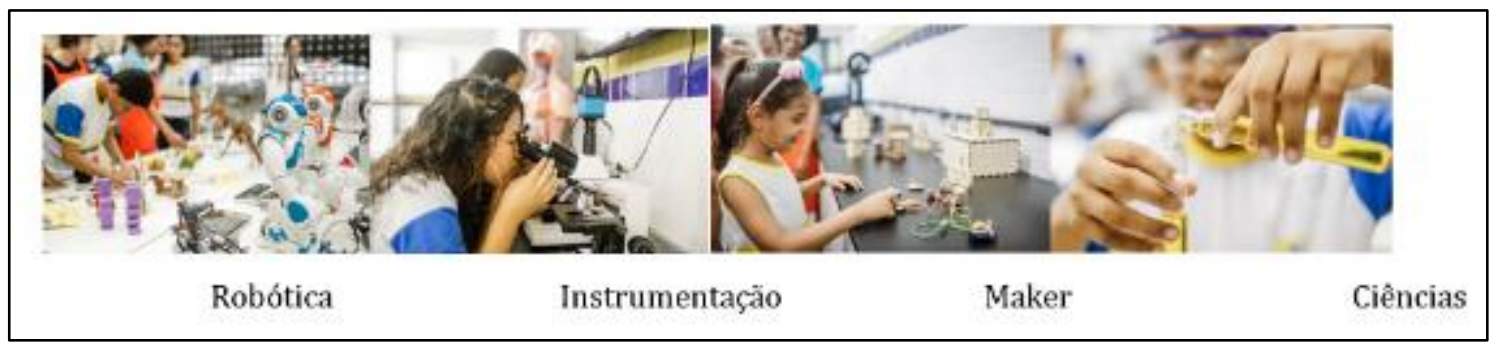

Figura 1: Crianças fazendo diferentes usos dos recursos dos laboratórios.

\section{LABORATÓRIO DE CIÊNCIA E TECNOLOGIA}

Neste espaço, o objetivo é levar os estudantes a aprender conceitos, trabalhando com problemas reais, a partir do levantamento de hipóteses, sobre os fenômenos e conteúdo, buscando respostas por meio da observação, experimentação, investigação, na perspectiva da integração do uso dos Laboratórios de Ciência e Tecnologia (LCT). Ele está sendo apresentado aqui, a partir de seis seções: arquitetura geral do laboratório, estrutura física, gestão, dinâmica de funcionamento, a prática no laboratório e atividades desenvolvidas, conforme descrito a seguir.

\subsection{Arquitetura Geral do Laboratório}

A arquitetura e a combinação de diversos recursos, como materiais, máquinas e ferramentas, deve permitir a realização da maior parte das atividades previstas para os projetos. Para facilitar a distribuição de todo material, máquinas e ferramentas à disposição, esses itens são organizados por quadrantes. Alguns destes recursos são de uso geral, podendo ser utilizados em projetos de qualquer quadrante, como a Lousa digital,

Impressora laser em cores, TV para exibição de trabalhos de grupos, programas de TV por internet e conversão da tela do tablet em tela maior para compartilhamento por todos. 
Novos materiais demandados por ocasiões especiais não previstas, devem ser adquiridos com os instrumentos de compras regulares destinados a esse tipo de laboratório na escola.

Na figura 2 temos a representação do laboratório como quatro quadrantes. No entanto, essa ilustração é só uma representação esquemática de atividades que normalmente são realizadas em espaços diferentes. No referido laboratório, não há divisão geográfica para realização das atividades. Em muitos casos o laboratório pode ser preenchido por um único desses quadrantes. Na maior parte dos projetos, que tem caráter interdisciplinar, os quadrantes estão geograficamente misturados e indistintos especialmente.

A arquitetura e o material disponível no laboratório permitem trabalhar de maneira multidisciplinar, com uma diversidade de experiências combinadas como se existissem quatro laboratórios em um único espaço, o qual denominamos de quadrantes: Q1 - Ciências; Q2 Instrumentação; Q3 - Robótica/Programação e Q4 - Espaço Maker, conforme apresentado na figura 2 , a seguir.

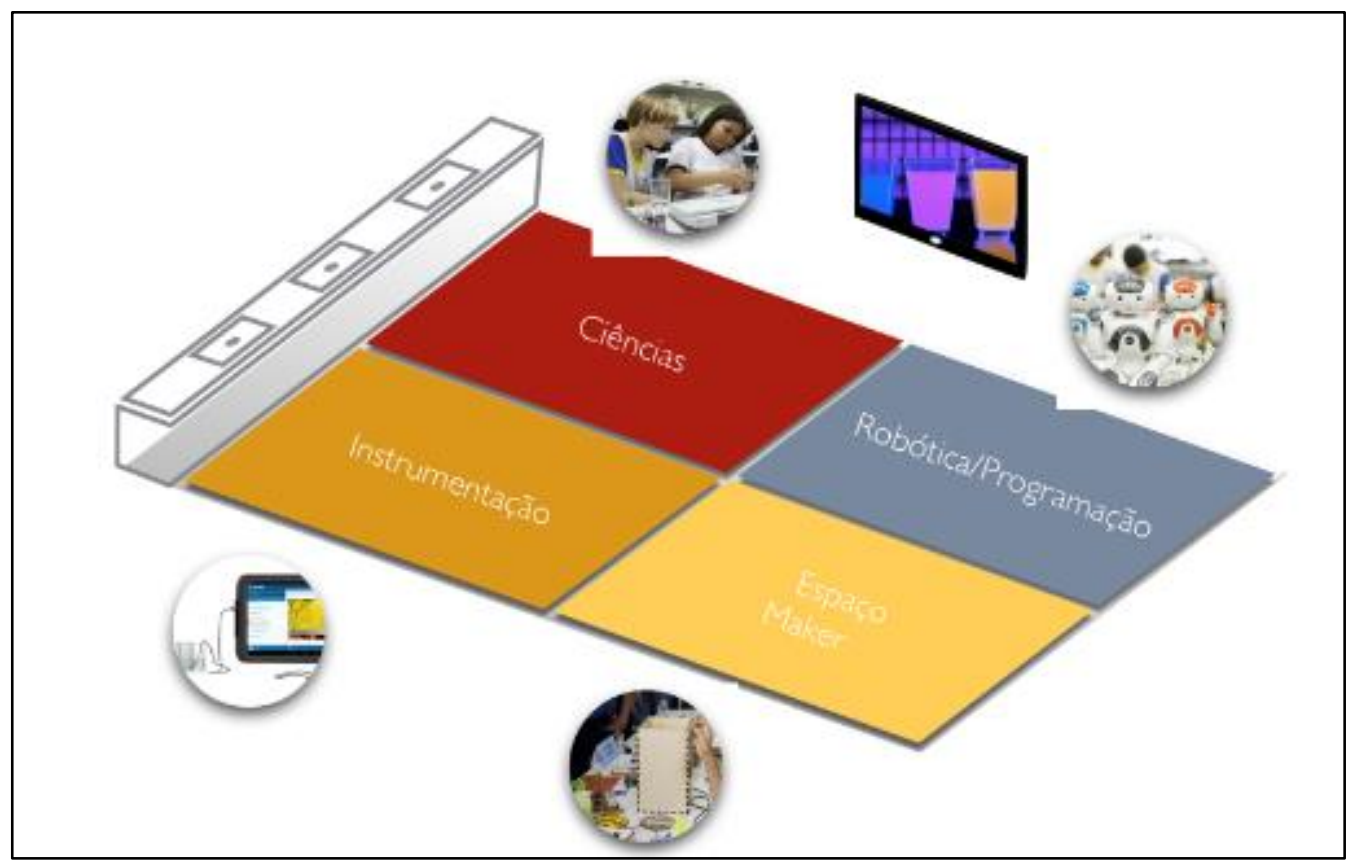

Figura 2: Os quatro quadrantes do laboratório.

O quadrante Q1: Ciência - é um laboratório de ciência tradicional com vidrarias, reagentes químicos, montagens para estudo do movimento e da luz, material para o estudo da biologia etc. Neste quadrante há kit experimental de Biologia, Física, Matemática e Química.

O quadrante Q2: Instrumentação - equipamentos de medida e detecção que amplificam o alcance dos sentidos humanos e dão maior precisão como balanças semianalíticas, microscópios binoculares e trinoculares, tablet Intel equipado com câmera com lente de aumento, entrada para sensores e um software especial (LabCam) que o transforma em um equipamento sofisticado de medida e obtenção de vários tipos de dados de imagem e outros sensores. Neste quadrante de

RBPG, Brasília, v.15, n. 34, 2019.

Experiências Inovadoras 
Instrumentação científica estão disponíveis os microscópios, Balança de precisão, Instrumentos de medida, Tablets educacionais com sensores para medidas sofisticada de movimento e tempo.

O quadrante Q3: Robótica e Programação - conta com os kits de robótica, Kits Arduinos, Tablets/notebooks para programação, Kits Lego, Componentes de mecânica e eletrônica para robótica.

O quadrante Q4: Espaço Maker - encontra-se Impressora 3D ou pistola de impressão 3D, Cortadora a laser, Kits de marcenaria, Kits de mecânica e Kits de eletrônica.

\subsection{Estrutura física}

O espaço físico do laboratório deve corresponder à realização de atividades de quatro tipos de espaço físico utilizados em ciência, tecnologia e inovação: laboratório de ciência convencional, laboratório de instrumentação científica, laboratório de robótica e programação e espaço Maker (MARAVILHAS, 2016).

Diversas configurações são permitidas na ocupação do espaço, de um ambiente quase vazio sem móveis no meio, a uma sala com bancadas para desenvolvimento de várias atividades. Portanto, a capacidade das configurações para as atividades, é em parte, fornecida por móveis, materiais, máquinas e ferramentas de posição de estudantes e professores. Esta estrutura física, ainda assim, recebe configurações especificas de pequenas reformas para adaptação do espaço disponível às atividades.

O principal elemento físico para a realização deste laboratório é um espaço que dê condições de realização das atividades nas escolas e que sirva a todas as disciplinas. Para que esse espaço permita as diversas possibilidades de práticas, deve ser um espaço flexível com capacidade para uma turma inteira de anos finais, 36 estudantes, em trabalho de oficina, como movimentação e uso de ferramentas. Ou, em casos especiais de restrição, deve ter capacidade para, no mínimo, um terço de uma turma, 12 estudantes, em dinâmicas em que sejam possíveis manter a maior parte em sala de aula, ou outro local adequado para o tema abordado, e a outra parte menor no laboratório. Muitos projetos avulsos ou de clubes (de robótica, de ciência, etc.) são realizadas por uma parte da turma. No entanto, há limitação para as escolas que não tem espaço realizarem as atividades com todos os estudantes da turma participando ativamente de práticas no laboratório.

Devido à grande diversidade de estrutura física das escolas da rede municipal de ensino do Recife, temos dois tipos básicos de laboratório que denominamos de:

- Laboratório tipo A, com uma área de $100 \mathrm{~m}^{2}$ para uma turma de 36 estudantes; e

- Laboratório tipo B, com uma área mínima de $40 \mathrm{~m}^{2}$ - para metade de uma turma de 36, ou seja, 18 alunos em atividade que não precise de muito espaço, $2 \mathrm{~m}^{2} /$ aluno.

\subsubsection{Laboratório tipo A: Escola com estrutura maior}

As escolas que permitirem a instalação de laboratórios maiores, denominados de tipo A, possibilita que o espaço possa ser adaptado para comportar todos os estudantes de uma turma de anos finais em atividade prática. As bancadas, armários e cadeiras, devia ocupar o meio do

RBPG, Brasília, v.15, n. 34, 2019.

Experiências Inovadoras 
laboratório em várias configurações de montagem, incluindo uma liberação do espaço para deixar a sala quase vazia em atividades com uma grande arena de robótica no piso, sempre que tirar os móveis da sala. Portanto, esses móveis devem ter característica de rebatimento e de fácil mobilidade para empilhar. Exemplos de configurações deste espaço estão ilustrados na figura 3.

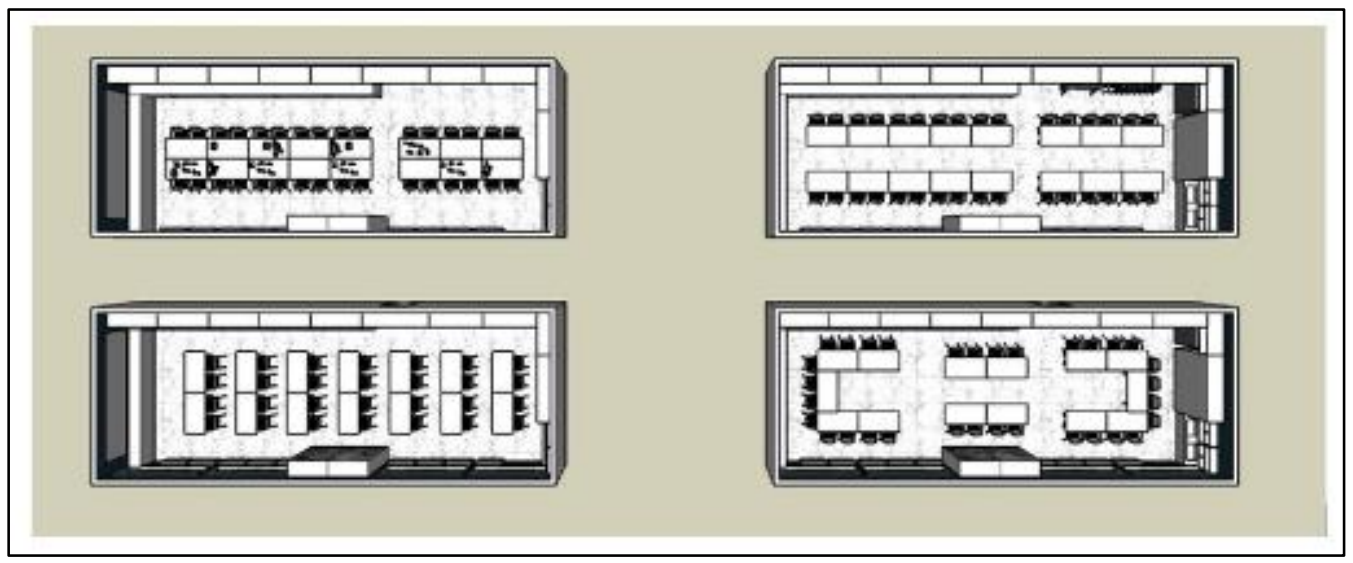

Figura 3: Possibilidades de organização do laboratório para atividades diferentes sem precisar deslocar os móveis para outro ambiente.

As outras duas figuras, 4 e 5, na sequência representam uma visão perspectiva com um exemplo da decoração interior dos móveis e material de laboratório. Cadeiras e mesas são reclináveis e rebatíveis permitindo empilhamento que empacote os móveis em espaço mínimo. As figuras mostram também grandes ilustrações nas paredes para aumentar a motivação e identificação de professores e estudantes pelos temas científicos e tecnológicos. Elas podem ser trocadas entre laboratórios de diferentes escolas após um período de exposição com o objetivo de renovar a motivação.

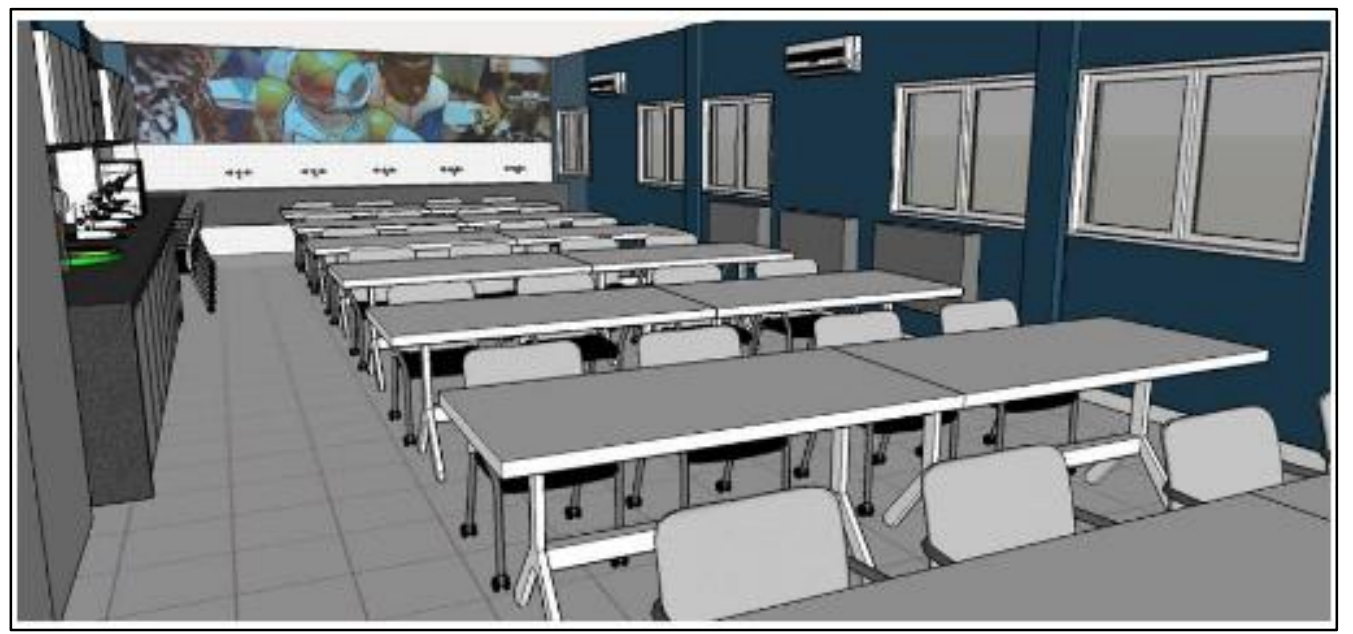

Figura 4: Laboratório do tipo A (maior) permite que uma turma inteira dos anos finais do Ensino Fundamental caiba para atividades que não exigem muito espaço.

RBPG, Brasília, v.15, n. 34, 2019.

Experiências Inovadoras 


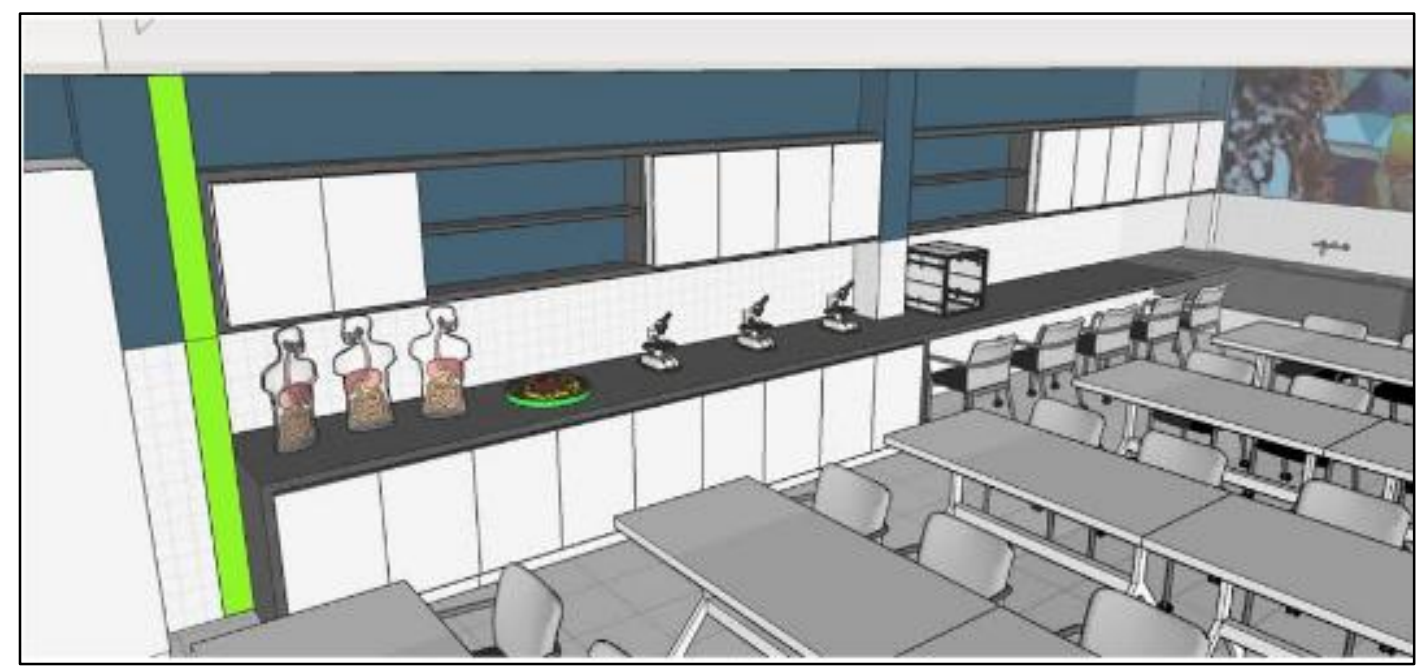

Figura 5: O laboratório pode adquirir estrutura até de uma sala de aula convencional, se o professor preferir, mesmo com as bancadas fixas dos vários recursos dos quatro quadrantes nas laterais.

\subsubsection{Laboratório tipo B: Escolas com pouco espaço}

Nas escolas em que não seja possível instalar uma estrutura mais adequada são realizadas adaptações para pequenos laboratórios que possam caber, pelo menos, um terço da turma por vez. Nesses espaços, as cadeiras podem ser substituídas por bancos empilháveis e as mesas podem ter tamanho menor em relação ao laboratório de tipo A. Alguns equipamentos de dimensões maiores também pode ser que fiquem fora, noutro espaço. Cada caso é estudado especificamente, mas o tipo básico é o descrito aqui. As figuras 6 e 7 apresentam um exemplo deste tipo de laboratório que deve ser o de menor espaço encontrado.

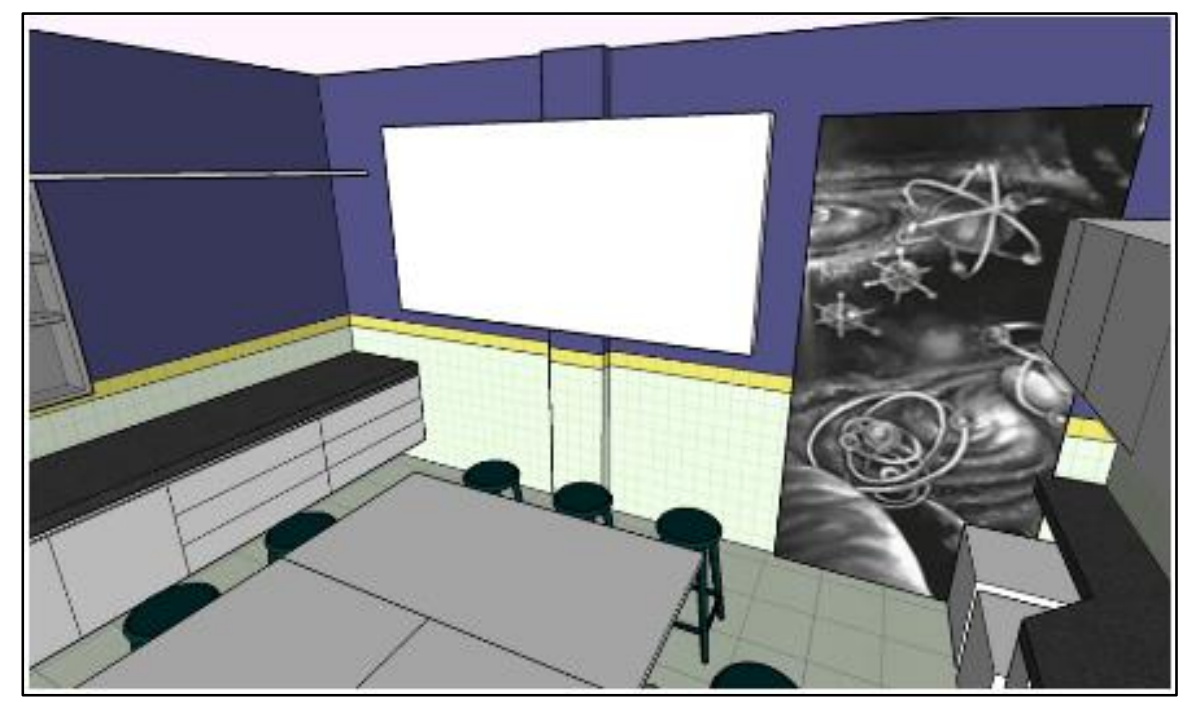

RBPG, Brasília, v.15, n. 34, 2019.

Experiências Inovadoras 
Figura 6: Laboratório de tamanho menor (tipo B) tem algumas mudanças de móveis e estrutura para acomodar, pelo menos, um terço de uma turma de 36 estudantes.

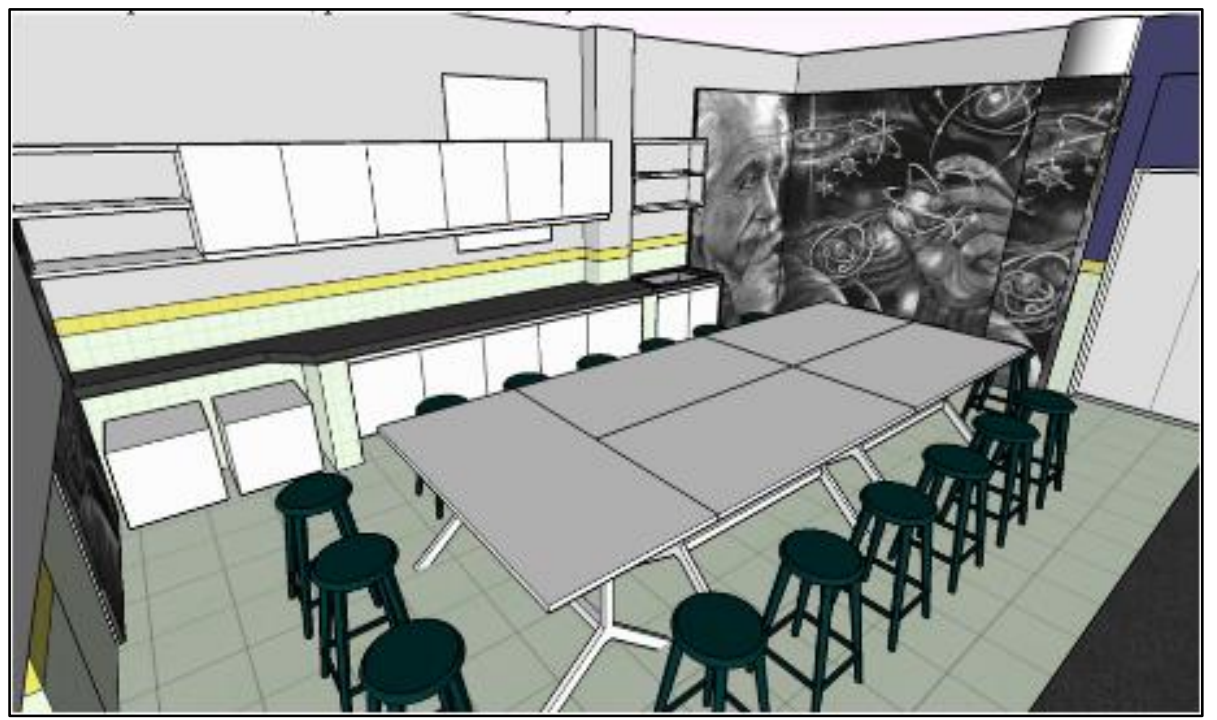

Figura 7: Bancos pequenos e empilháveis são adequados para as atividades. Mesmo com tamanho menor, a decoração com grandes painéis de parede é importante para tornar o ambiente sempre estimulante para os estudantes.

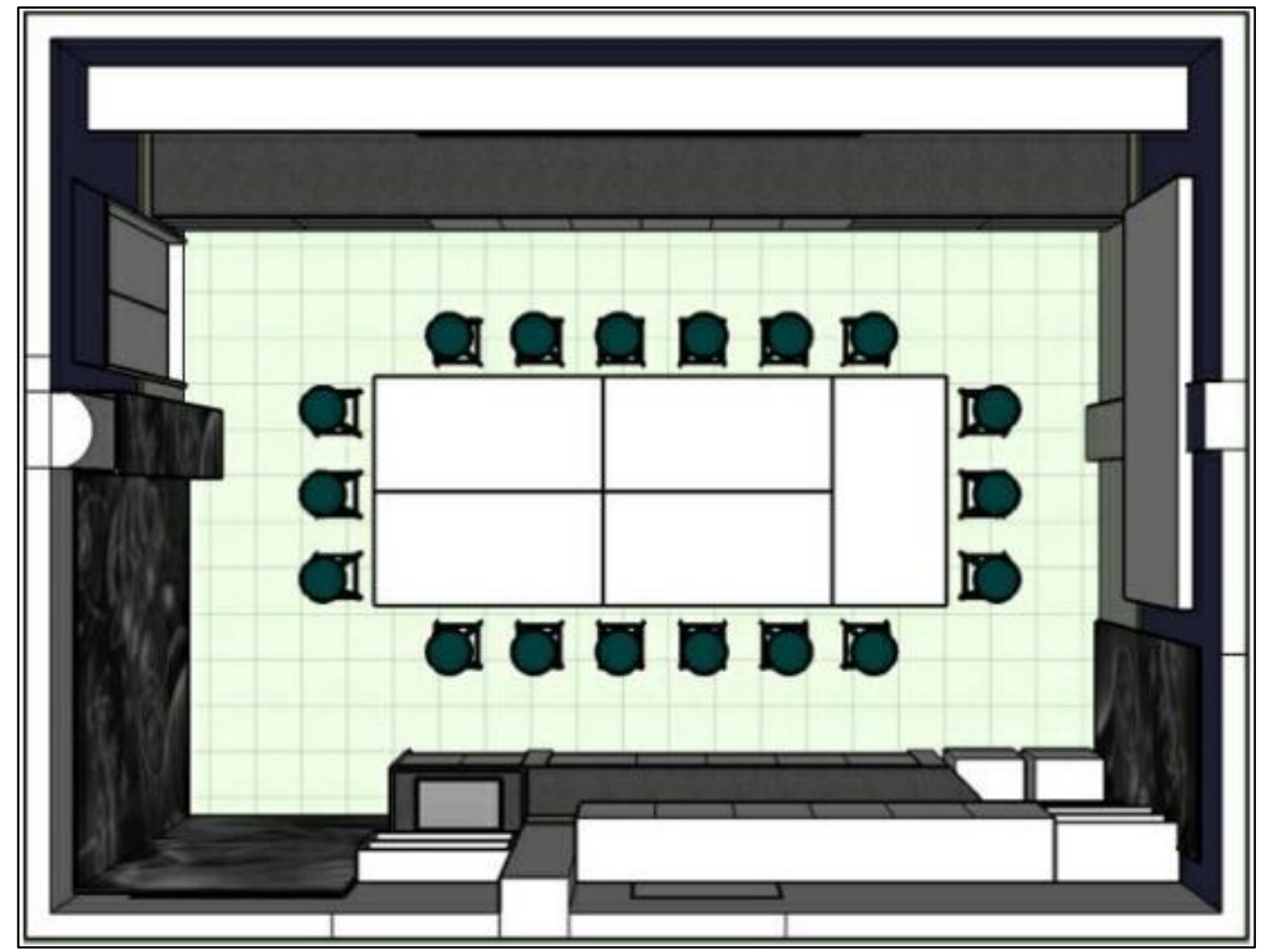

RBPG, Brasília, v.15, n. 34, 2019.

Experiências Inovadoras 
Figura 8: a falta de espaço diminui o leque de configurações possíveis e adequadas de móveis, mas ainda é possível a realização da maior parte das experiências e projetos com um conjunto menor de estudantes.

\subsection{Gestão do Laboratório}

A gestão do laboratório é feita por uma Coordenação Geral, Assessorias e instituições parceiras, Coordenadores locais em cada laboratório e monitores, como ilustrado na figura 9. O coordenador geral deve possuir experiência em trabalho de Pesquisa, Robótica e Cultura Maker.

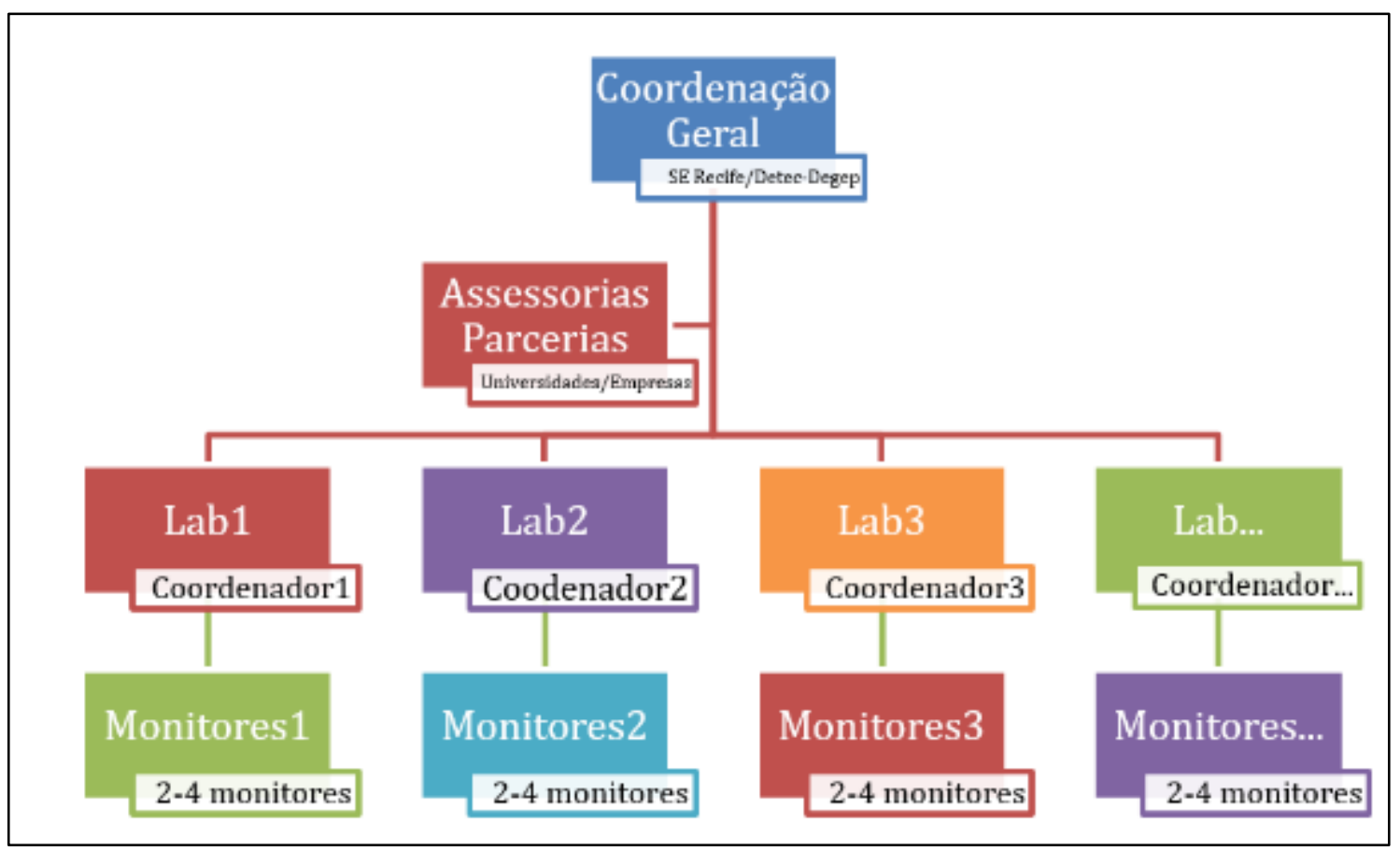

Figura 9: Organograma e estrutura hierárquica necessárias para o funcionamento da rede de laboratórios.

\section{Coordenação Geral do Projeto}

É responsável pela gestão com abordagem na formação, implantação, avaliação, manutenção, seleção de pessoal e pelo gerenciamento de contratos e convênios necessários para o funcionamento e relacionamento com as instituições de ensino e pesquisa e empresas de inovação nas áreas afins.

\section{Assessorias/Parcerias}

Como suporte à gestão da rede de laboratórios, contamos com assessores, instituições parceiras e consultores.

O acompanhamento das instalações é realizado pelas assessorias de planejamento e avaliação e pedagógico-científica. A Assessoria de Planejamento e avaliação é responsável por 
acompanhar a instalação dos laboratórios e seu funcionamento com as atividades anuais. Esta assessoria, acompanha o andamento do projeto no sentido de direcioná-lo ao cumprimento das metas e objetivos propostos. Acompanha também as ações com o fim de fazê-las acontecer no tempo previsto, de forma adequada usando os recursos necessários. Avalia as etapas, tempo de execução das ações e cumprimento dos prazos determinados até sua conclusão.

A Assessoria Pedagógico-Científica é responsável pela produção documental científica. Sistematização dos projetos e ações desenvolvidas, com fim de produzir material para publicações e divulgação científica do projeto.

\section{Consultores}

Os consultores são pesquisadores de instituições de ensino superior ou técnicos altamente especializados que dão suporte ao desenvolvimento das atividades dos laboratórios, a formação de professores e monitores, promovendo a inovação e atualização das práticas e concepções pedagógicas, técnicas e científicas.

\section{Coordenador de Laboratório de Ciência e Tecnologia}

Cada laboratório possui um coordenador, responsável pelo funcionamento do Laboratório de Ciências e Tecnologia. Envolve os professores e estudantes nas práticas de ciência e tecnologia a partir da criação e do desenvolvimento de desafios e situações problema. Também orienta o trabalho do professor para o uso das tecnologias disponíveis no laboratório, mediando a ação pedagógica dos professores com os conteúdos das diferentes áreas (química, física, biologia, astronomia, robótica, programação e arte).

\section{Monitor de Laboratório}

Cada laboratório deve ter dois monitores de apoio em cada turno. Normalmente é um estagiário de nível superior, estudante universitário de Iniciação Científica (PIBIC), ou de Iniciação Tecnológica (PIBIT) ou ainda de Iniciação à Docência (PIBID). Sua principal função é o apoio ao coordenador do laboratório no funcionamento e desenvolvimento de atividades práticas junto aos estudantes.

\subsection{Dinâmica de Funcionamento}

O funcionamento e adesão de professores ao uso do laboratório passa por uma sólida base de apoio de pessoal que evite que um professor, quando necessitar usar, não tenha que procurar a chave para laboratório, depois tentar abrir sozinho, procurar material e reagentes, pois assim o tempo da aula já será consumido e o rendimento pedagógico da atividade será baixo.

Para o melhor aproveitamento, o uso do espaço ocorre por agendamento eletrônico por contas educacionais da Google no domínio @educ.rec.br, sempre precedida do nome do laboratório (ex.: labpedroaugusto@educ.rec.br). Ao agendar a atividade, o professor pode 
conversar com o coordenador do laboratório para explicar exatamente o que desejar fazer. Quando for usar, todo o material e montagem estará pronto e contará ainda com o apoio técnico da equipe de laboratório.

\subsection{A Prática no Laboratório}

O laboratório é um espaço de uso flexível que vai da ciência, passando por matemática, até a programação de práticas makers. No entanto, as listas das principais práticas podem ser resumidas nos itens a seguir:

- Trabalho em grupo com a supervisão do professor e orientação do Gestor do laboratório;

- Apresentação de situações-problemas com diferentes complexidades (os problemas devem ser identificados, pelos estudantes, considerando a sua realidade e o contexto local);

- Estudo de situações não fictícias para provocar o estudante a buscar soluções e novos conhecimentos ao se deparar com uma situação real;

- Apresentação e formulação de hipóteses;

- Registro do processo de pesquisa (diário de laboratório);

- Discussão com a formulação de questões e objetivos de aprendizagem (com base das diretrizes curriculares);

- Retomada da discussão com o grupo no laboratório já com o novo conhecimento adquirido, alinhando discussões prévias, conhecimento científico e teoria;

- Os resultados devem se voltar para situações reais;

- Apresentação científica das atividades.

\subsection{Atividades Desenvolvidas}

Entre as diversas atividades que podem ser desenvolvidas, destacamos algumas de maior frequência atual:

- Qualificação dos professores das escolas para a implantação e uso do laboratório multidisciplinar, para a utilização e inserção dos laboratórios dentro do currículo escolar;

- Exploração e uso da impressora 3D, e de corte a laser. O uso da impressora 3D possibilita a transição e materialização de ideias para o mundo real e sua vivência na prática, de maneira dinâmica e interativa. Além disso, auxilia o estudante na exploração de novos conhecimentos e na ampliação de conhecimentos já adquiridos;

- Robótica e programação;

- Olimpíada de programação, robótica e games/jogos;

RBPG, Brasília, v.15, n. 34, 2019. 
- Fabricação digital de brinquedos educativos e demais objetos;

- Uso de simuladores virtuais;

- Projeção, medição e montagem de diferentes equipamentos, instrumentos e diferentes objetos;

- Experimentação em química, matemática, física, etc;

- Realização de um evento anual sobre Ciência e Tecnologia contemplando palestras, mesa redonda, oficinas, sessão de pôsteres, mostra científica e relatos de experiência;

- Intercâmbio para estudantes e professores com vistas à ampliação de conhecimentos e socialização de experiências; Quantificação (quantos professores e estudantes estarão participando) e qual tipo de evento (nacional ou internacional);

- Premiação: instituição do Prêmio Cientista Escola do Futuro-Celina Martelli;

- Participação em eventos - participação em quatro eventos anuais na área de Ciência e Tecnologia, sendo três eventos nacionais e um evento internacional;

- Familiarização com a linguagem de programação para busca de soluções baseadas em problemas reais; $\mathrm{e}$

- Realização das olimpíadas para compartilhar experiências das escolas e divulgação de boas práticas com tecnologias digitais.

\section{METODOLOGIA}

A base metodológica do Laboratório de Ciência e Tecnologia está centrada na aprendizagem por problematização (PBL), uso dos espaços makers com ferramentas digitais e tecnológicas, além de recursos tradicionais e a abordagem educacional multi e transdisciplinar STEAM que integra ciências, tecnologia, engenharia, artes e matemática, para identificar e resolver problemas, dos mais simples aos mais complexos, priorizando a implantação de aulas orientadas para a investigação e o trabalho com projetos, focando o aprender fazendo.

A ideia é que o professor (individualmente) e a escola (coletivamente) assumam essa metodologia como uma perspectiva de aprendizagem e desenvolvimento. Isso exige mudanças na escola e na maneira de pensar e organizar as aulas, os laboratórios, as atividades e os materiais. Destacamos que essa metodologia não requer uma grande modificação na estrutura física da escola, mas sim nos conteúdos e disciplinas e, sobretudo, na forma de pensar de professores e estudantes (ANDRADE, 2016), onde a reflexão e a crítica devem estar presentes. O funcionamento de toda essa estrutura a favor desta metodologia só será bem aplicado se o professor encontrar uma estrutura de apoio que o liberte das atividades iniciais de preparar o laboratório e deixar tudo pronto para a realização da atividade.

$\mathrm{Na}$ concepção do Laboratório de Ciência e Tecnologia, o grande propósito da abordagem educacional STEAM é materializar ideias e permitir implementar soluções, mesmo por crianças, a partir de técnicas de áreas profissionais ou mais avançadas do que os conteúdos curriculares apresentados cotidianamente aos estudantes. Na abordagem STEAM prioriza-se o trabalho em projetos e processo de construção, aplicando conceitos de ciências, robótica, 
programação, física, química, modelagem 3D, tecnologia, engenharia, arte, astronomia e matemática (THIBAUT, 2018).

Os Estados Unidos da América lançaram seu programa, frente à ameaça de ficarem para trás em comparação com outras nações que disputam a vanguarda do desenvolvimento tecnológico. Esse lançamento ocorreu durante o governo Obama com o projeto STEM 2026, ressaltando a importância das habilidades desenvolvidas por quase todos os setores da economia americana impulsionada pelas novas tecnologias. As premissas de desenvolvimento do projeto STEM 2026 (DEPARTMENT OF EDUCATION, 2016) são:

- Comunidades de práticas engajadas e em rede;

- Atividades de aprendizagem acessíveis que convidam a brincadeiras e riscos intencionais;

- Experiências educacionais que incluem abordagens interdisciplinares para resolver "grandes desafios";

- Espaços de aprendizagem flexíveis e inclusivos suportados por tecnologias inovadoras;

- Medidas inovadoras e acessíveis de aprendizagem;

- Imagens societais e culturais e ambientes que promovem a diversidade e a oportunidade com STEM.

A Metodologia PBL - Problem Based Learning (aprendizagem baseada em problemas) (LOPES, 2019), (SILVA, 2018) também deve ser aplicada nas diversas atividades no laboratório, estimulando o raciocínio investigativo durante o processo de aprendizagem. Diferente do método tradicional, em que a transmissão da informação é o foco principal da produção do conhecimento, a metodologia PBL estimula a atitude ativa do estudante (BOROCHOVICIUS, 2014).

O reforço sinérgico de STEAM com PBL (SIMAS, 2017) induz o estudante a ser protagonista na produção de conhecimentos, levando-o a 'colocar a mão na massa', experimentar, aprender fazendo, assim será possível construir seus próprios equipamentos, objetos e projetos (JACKIE, 2019), (ATHAYDE, 2003), (GRYNSZPAN, 2006), (SOUZA, 2011). No espaço maker, os estudantes estão desenvolvendo habilidades e competências necessárias ao século 21 , bem como conhecimentos tecnológicos utilizados na atual sociedade onde eles são os agentes de sua própria aprendizagem.

\section{RESULTADOS}

Os primeiros resultados ocorreram na fase piloto, em 2016, quando os testes foram feitos no Centro de Tecnologia, Educação e Cidadania.

\subsection{Patente}

Entre as atividades desenvolvidas, trabalhamos com o desenvolvimento de projetos de pesquisa de soluções tecnológicas. Um dos exemplos foi o registro de depósito de patente para o 
produto tecnológico correspondente ao sistema "nervoso" do robô humanoide Recife em desenvolvimento, a exemplo da próxima ilustração em sequência na Figura 11, envolvendo a autoria de dois professores e de um estudante da primeira escola a ter um laboratório instalado.

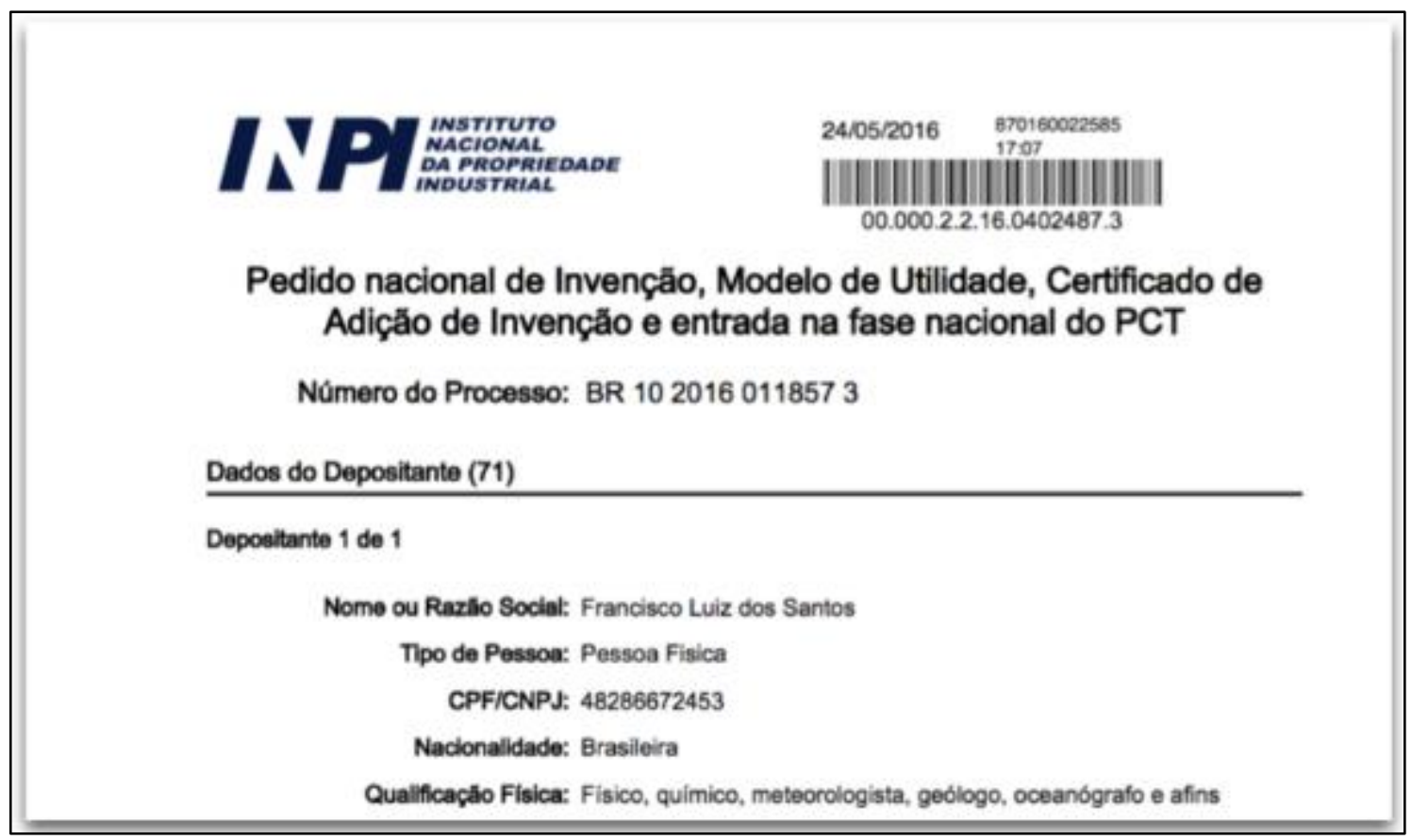

Figura 11: documento de depósito de patente (desenvolvida na fase inicial da implantação do primeiro laboratório com a participação de estudantes do Ensino Fundamental) do sistema "nervoso" de controle de um robô humanoide (especialmente desenhado para o robô Humanoide Recife) da distribuição de microcontroladores e suas interconexões de membros microcontrolados e um "cérebro" central.

\subsection{Publicações}

Nesta fase piloto a interação com as universidades se intensifica com desenvolvimento de pesquisas baseadas na formação de professores para atuar nos laboratórios. A parte mais expressiva dessa fase foi a publicação de sete artigos científicos nacionais e internacionais:

1. Amorim et al (2016), Robotics and Technological Innovation at School;

2. Amorim et al (2016), Integrando as Plataformas App Inventor e Arduino na Construção de um Humanoide;

3. Amorim et al (2016), Educational Robotics in Elective Discipline;

4. Barros et al (2015), Tablets na Educação Infantil;

5. Cavalcanti et al (2017), As Interações Curriculares entre Linguagens Tecnológicas e Base Comum: uma experiência de Educação em Tempo Integral;

6. Mendes et al (2016), Cinema na Escola: caminhos para aprender ciências; e 
7. Santos et al (2016), Methodological Innovations Mediated by Technology in Basic Education.

\subsection{Linha do Tempo Visual dos Laboratórios}

A instalação dos laboratórios envolve forte colaboração e boa comunicação entre os setores de tecnologia na educação, gestão pedagógica, gestão da rede e de infraestrutura geral de obra civil da Secretaria de Educação. Sem isso, deixamos pendências que podem impedir que todos as atividades previstas deixem de ser executadas por estudantes e professores. Segue sequência de fotografias na linha do tempo de alguns destes laboratórios, da fase inicial ou de inexistência até a instalação e o seu funcionamento.

\section{Laboratório Pedro Augusto}

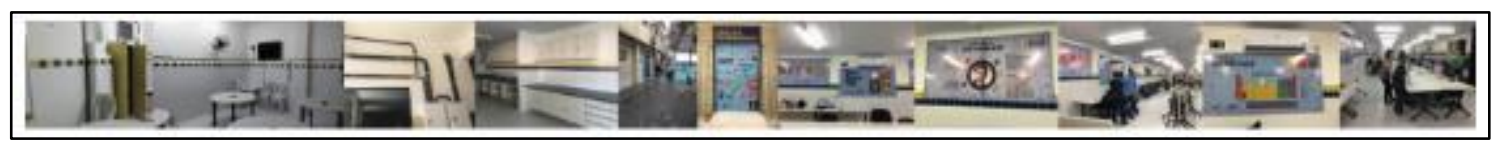

\section{Laboratório Antônio de Brito Alves}

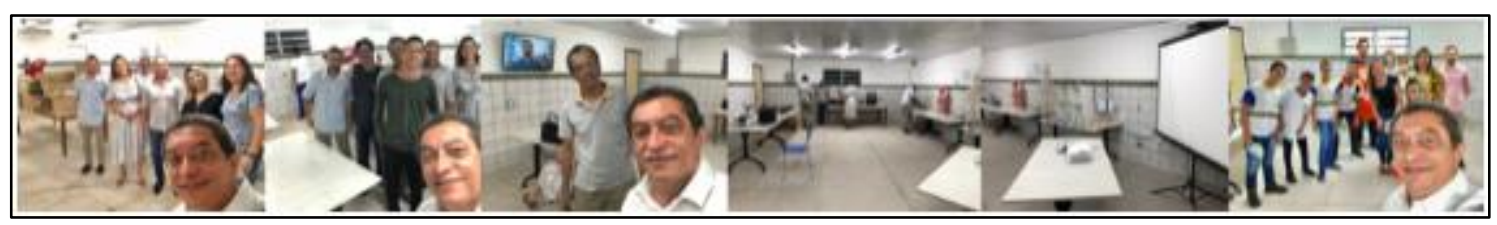

\section{Laboratório Rodolfo Aureliano}

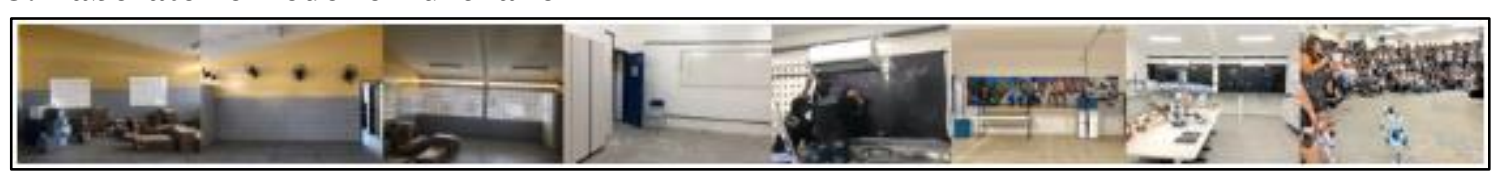

\section{Laboratório Josué da Costa Porto}

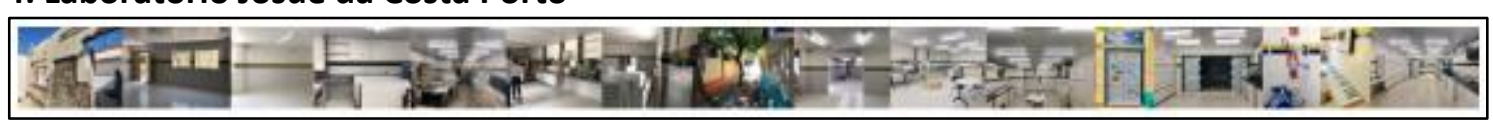

\section{Laboratório Antônio Farias Filho}

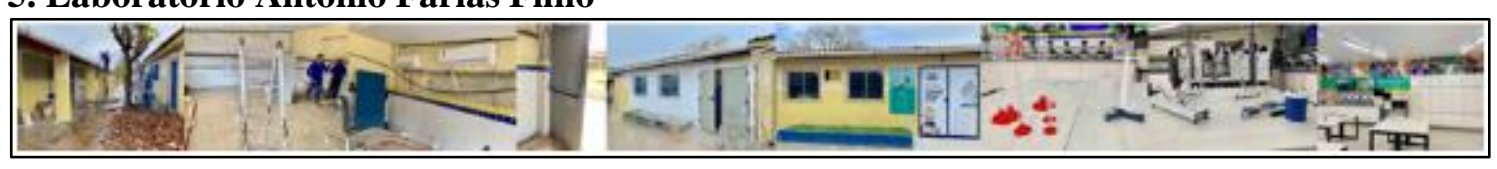

\section{Laboratório Dom Bosco}

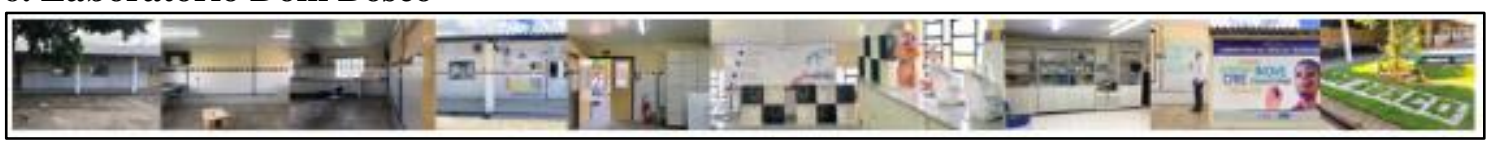

RBPG, Brasília, v.15, n. 34, 2019.

Experiências Inovadoras 


\subsection{Atividades desenvolvidas nos Laboratórios}

As principais atividades desenvolvidas atualmente são:

- Demonstrações de experimentos e de fenômenos;

- Aulas práticas;

- Trabalhos e projetos de pesquisa para feiras de conhecimentos ou ciências;

- Projetos dos clubes de ciência, robótica e maker;

- Projetos com pesquisadores das universidades; e

- Práticas pedagógicas extraordinárias, além das citadas nos itens acima.

\subsection{Repercussão na vida dos estudantes e professores}

Uma contribuição importante da implantação desse espaço nas escolas pode, em parte, vir dos depoimentos apresentados por estudantes e professores. O nível de aceitação dos laboratórios tem sido alto, a exemplo da declaração coordenador do primeiro laboratório, Leandro Agra: "Se deixar os alunos passam o dia no laboratório. Às vezes tenho que almoçar rapidinho para voltar porque eles querem ficar o tempo todo". O estudante Nicolas também declara: "É muito legal ficar no laboratório, gosto muito". (JCONLINE, 2018).

O gosto pela mão na massa, a vontade de ficar mais tempo no laboratório, a mudança de comportamento dos estudantes, diante este novo espaço de aprendizagem, pode ser observado nas declarações de Adrielly Maria da Silva, 14 anos, do $8^{\circ}$ ano: “Às vezes só aula é chato, enjoa. No laboratório a gente faz experimentos, aprende mais". Raissa Gonçalves, 12 anos, do $7^{\circ}$ ano que construiu com outro colega uma mão com material termoplástico biodegradável, a partir de uma impressora 3D, afirma: "Os professores ensinam de um jeito diferente. Quando tenho aula vaga, nos intervalos, ou quando largo mais cedo sempre venho para cá". (JCONLINE, 2018).

A Assessora de Comunicação da Secretaria de Educação, Cáthia Santos, também registrou depoimentos nesta mesma direção, conforme relata Glaybson Anderson, 13 anos, do $7^{\circ}$ ano: "O laboratório contribuiu para vários projetos na minha vida. Antes eu era desinteressado pelos estudos. Com a inauguração do laboratório tem novos projetos como robótica, o maker, e ciências, que me incentiva a estudar".

\subsection{Despertar para novos horizontes de futuro}

O interesse das crianças e jovens no envolvimento prático com ciências e tecnologias, robótica programação e cultura maker no laboratório tem sido grande. As práticas têm conduzido a uma visão de futuro, de sonhos e despertar do interesse pelas próprias profissões, conforme depoimentos dos próprios estudantes à Assessora de Comunicação Cáthia Santos:

Adrielly, 15 anos, do $9^{\circ}$ ano: "Antes do projeto maker chegar na escola eu não tinha perspectiva do futuro, não tinha interesse em algo profissional, mas agora eu desejo muito ser arquiteta".

RBPG, Brasília, v.15, n. 34, 2019.

Experiências Inovadoras 
Esther Lins, 14 anos, do $9^{\circ}$ ano: "O laboratório e a equipe que trabalha nele, pôde colaborar para os meus estudos em geral, do dia a dia. Mas graças a projetos como o maker eu pude desenvolver interesse pela arquitetura gráfica".

Débora Lícia, 14 anos, do $9^{\circ}$ ano: "O laboratório e os equipamentos me influenciou a pensar em análises clínicas e com isso me levou a pensar na área de oncologia que estuda bastante esse negócio de análise".

Marcos, do $6^{\circ}$ ano: "O laboratório foi muito importante pra mim porque eu decidi, depois que tive contato com robótica e clube de ciência, que quero fazer computação".

Tierry Tavares, 13 anos: "O laboratório foi fundamental para que eu pudesse aprender coisas novas, pra que eu pudesse aplicar os conhecimentos que eu aprendi na sala de aula, inclusive na escolha com relação ao profissionalismo. Através da robótica eu percebi que algumas funcionalidades, alguns maquinários são parecidos com o corpo humano isso despertou o interesse um pouco maior de fazer medicina".

\section{CONSIDERAÇÕES FINAIS}

Os laboratórios têm uma agenda concorrida principalmente pelo interesse dos jovens estudantes de aprender explorando, testando, fazendo, experimentando e se divertindo com a busca própria por resposta ou explicação dos fenômenos e pela construção ou concretização de suas próprias ideias. Uma parte desse desenvolvimento é percebida no progresso que alcançam na sequência acadêmica nas melhores escolas de Ensino Médio da região, a exemplo do êxito na entrada das escolas técnicas de referência que exigem exame de admissão (PREFEITURA DO RECIFE, 2015). Há dois anos, o total de estudantes egressos que conseguiam ingressar nessas escolas era em torno de duzentos e hoje se aproxima de quinhentos, em grande parte devido ao programa de revisão de conteúdos em aulões denominado Ondatec, mas há contribuições gerais de um conjunto de ações de engajamento de maior motivação para os estudos que estão ocorrendo nas escolas, entre eles a principal feira de conhecimento da rede municipal (FECON-Recife) e as atividades nos laboratórios de ciência e tecnologia.

Resultados parciais obtidos nestes laboratórios têm mostrado a importância da criação, desenvolvimento e construção de objetos por parte dos estudantes e a motivação que os mesmos adquirem ao longo do tempo e dos resultados positivos apresentados à sociedade, assim como a responsabilidade que os mesmos adquirem com o mundo ao seu redor. No laboratório da escola Dom Bosco, por exemplo, diversos projetos estão sendo desenvolvidos pelos estudantes: compostagem com cascas de frutas da merenda escolar e a produção de adubo para utilizar nas plantas das próprias hortas escolares. O desenvolvimento de robôs hidráulicos com peças feitas de papelão reciclado; medição do $\mathrm{pH}$ da água sanitária, extrato de repolho; identificação de um novo tipo de linguagem pelos jovens; discussão de diversos problemas que enfrentam no dia a dia, como a queda de barreira dos morros onde muitos deles moram; a produção de sabonetes a 
partir de extrato de plantas medicinais que são utilizados pelos próprios estudantes para o controle com a saúde, são exemplos.

Estudantes que frequentam estes laboratórios tem adquirido conhecimento e desenvolvido competência em ciência, tecnologia, engenharia, matemática e tem feito opção por estas áreas, a exemplo de Maryllia Willyane Félix, campeã brasileira de robótica 2015 que cursa Eletrônica, na atualidade e Eduarda Oliveira, campeã brasileira de robótica de 2016 que afirma que o seu desejo não é só de continuar fazendo coisas que são soluções para problemas cotidianos, mas a nova consciência de que "quero impactar a vida das pessoas aqui e no mundo todo".

O Recife se tornou, recentemente, a $34^{\mathrm{a}} \mathrm{Fab}$ City do mundo (ALVES, 2019). Grande parte da proposta do Recife (neste ano em Amsterdã) envolve o que estas crianças estão fazendo localmente, pensando em soluções para os problemas onde elas estão envolvidas e querendo impactar globalmente. A cidade ganhou uma rede de laboratórios "espalhada" pelas escolas que permite sonhos e realizações de uma Fab City, como foi mostrado na Suécia em 2019 na candidatura do Recife. Segundo Edgar Andrade, "Uma das principais discussões levantadas em Amsterdã é sobre como conectar educação e cidade. É exatamente isso que estamos materializando no Recife, tentando mostrar o olhar das crianças da rede pública para pensar e criar soluções para problemas reais. Problemas que impactam a vida de muita gente" (ALVES, 2019).

As nossas crianças ou jovens estão dando palestras em eventos para adultos (como ocorreu no Rec'n'Play de 2019 em Recife) sobre suas visões e realizações e estão convidados para levar ao Canadá em 2020. O Brasil não será um país desenvolvido se suas crianças não se desenvolverem e os Laboratórios de Ciência e Tecnologia que estão sendo implantados na Rede Municipal de Ensino do Recife estão dando uma grande contribuição a esse desenvolvimento. O sentimento dos gestores municipais também é de importante continuidade desta ação no município, como relata o Secretário de Educação, Bernardo D’Almeida: “....”e o prefeito Geraldo Julio: “....".

A importância da mão na massa dos espaços makers, aliado a resolução de problemas e abordagem STEAM tem levado a mudança destes jovens por uma consciência de futuro promissor. A participação em diversos projetos e até o conhecimento de outros países, dentro dos nossos programas de propiciar essa ampliação de visão de mundo e experiências que vão além do laboratório, permite-nos afirmar que eles se tornam pequenos para os sonhos e ao mesmo tempo se tornam modelos a serem seguidos, a exemplo de Ryan Vinícius Morais, campeão da Olimpíada Brasileira de Robótica de 2016. Segundo Vanessa Silva Santos, mãe de Ryan: "O objetivo de Ryan foi alcançado. Há uns anos, não imaginava que meu filho teria um desempenho tão bom estudando em uma escola pública... Na rua em que moramos, na comunidade da Coreia, no Cordeiro, as crianças dizem que querem ser como Ryan quando crescerem. Tenho muito orgulho dele" (Prefeitura do Recife, 2015).

\section{REFERÊNCIAS}

\section{ALVES, P. Recife passa a integrar rede internacional de cidades para se tornar autossustentável até 2054. 2019. Disponível em:}


<https://g1.globo.com/pe/pernambuco/noticia/2019/06/20/recife-integra-rede-internacional-decidades-que-devem-se-tornar-autossustentaveis-ate-2045.ghtml>. Acesso em: 5 nov. 2019.

AMORIM, J. C. et al. Robotics and technological innovation at school. In: INTERNATIONAL CONFERENCE ON EDUCATION AND NEW LEARNING TECHNOLOGIES, 2016, Barcelona. Proceedings... Barcelona: EDULEARN, 2016a. p. Disponível em: $<\underline{\text { https://www.semanticscholar.org/paper/ROBOTICS-AND-TECHNOLOGICAL- }}$ INNOVATION-AT-SCHOOL-AmorimSantos/9f00757f8563d52e700fed7211604a1212eaff24>. Acesso em: 2 nov. 2019.

AMORIM, J. C. et al. Educational Robotics in Elective Discipline. In: EUTIC 2016. Network Logic and New Forms of Governance, 2016, Zakynthos: EUTIC 2016b, p. 164-173.

AMORIM, J. C et al. Integrando as Plataformas App Inventor e Arduino na Construção de um Humanoide. In: WORKSHOP DE INFORMÁTICA NA ESCOLA, 2016, Uberlândia. Anais... Uberlândia. Disponível em: 〈https://br-ie.org/pub/index.php/wie/article/view/6622/4533〉. Acesso em: 5 nov. 2019.

ANDRADE, F. de O.; NUNES, A. K. F.; LIMA, E. dos S. A contribuição da robótica educacional para o uso de metodologias ativas no ensino básico. In: SIMPÓSIO INTERNACIONAL DE EDUCAÇÃO E COMUNICAÇÃO, 7, 2016, Aracajú. Anais... Aracajú: SIMEDUC. Disponível em: $<$ https://https://eventos.set.edu.br/index.php/simeduc/article/view/3338>. Acesso em: 5 nov. 2019.

ATHAYDE, B. de C. et. al. Abc na educação científica/ mão na massa - análise de ensino de ciências com experimentos na escola fundamental pública paulista. In: ENCONTRO NACIONAL DE PESQUISA EM EDUCAÇÃO EM CIÊNCIAS, 4, 2003, Bauru. Anais... Bauru: INPEC. Disponível em: <https:// https:// http://abrapecnet.org.br/enpec/ivenpec/orais/ORAL026.pdf $>$. Acesso em: 4 nov. 2019.

BARBOSA DA SILVA, A. et. Al. Problem-based learning A proposal for structuring PBL and its implications for learning among students in an undergraduate management degree program. REGE Revista De Gestão, v. 25, n. 2, p. 160-177, 2018. Disponível em: <http://www.revistas.usp.br/rege/article/view/147511>. Acesso em: 5 nov. 2019.

BARRETT, T. W et al. A Review of University Maker Spaces. 122. Annual Conference \& Exposition. Seattle: American Society for Engineering Education, 2015. Disponível em: <https://www.asee.org/public/conferences/56/papers/13209/view>. Acesso em: 4 nov. 2019.

BARROS, L. D. de O. et al . Tablets na educação infantil. Revista Sensos-e, v. II, p. 9489, 2015. Disponível em: 〈http://sensos-e.ese.ipp.pt/?p=9489>. Acesso em: 2 nov. 2019. 
BELL, P. The school science laboratory: Considerations of learning, technology, and scientific practice. Washington: National Academy of Sciences, 2004.

BITTENCOURT, E; KOGUT, M. C. Perfil dos alunos das séries finais do ensino fundamental e sua influência na ação do professor. 2006. Disponível em:

$<$ https://www.researchgate.net/publication/267379520 perfil dos alunos das series finais do _ensino fundamental e sua influencia na acao do professor>. Acesso em: 5 nov. 2019.

BLIKSTEIN, P; MARTINEZ, S. L; PANG, H. A. Constructing Modern Knowledge Press

Torrance. 2017. Disponível em: <cmkpress.com〉. Acesso: 2 nov. 2019. 2017.

BOROCHOVICIUS, E.; TORTELLA, J. C. B. Aprendizagem Baseada em Problemas: um método de ensino-aprendizagem e suas práticas educativas. Ensaio: aval. pol. públ. Educ., Rio de Janeiro, v. 22, n. 83, p. 263-294, abr./jun., 2014. Disponível em:

<http://www.scielo.br/pdf/ensaio/v22n83/a02v22n83.pdf〉. Acesso em: 5 nov. 2019.

BRASIL. Prefeitura do Recife. Secretaria de educação do recife homenageia alunos aprovados em cursos técnicos. 2015. Disponível em:

$<$ http://www2.recife.pe.gov.br/noticias/23/12/2015/secretaria-de-educacao-do-recifehomenageia-alunos-aprovados-em-cursos-tecnicos>. Acesso em: 5 nov. 2019.

CAVALCANTI, A. C. B. As interações curriculares entre linguagens tecnológicas e base comum: uma experiência de educação em tempo integral. São Paulo, 2017.

DIÁRIO DE PERNAMBUCO. Rede municipal de ensino do Recife ganha novo laboratório de tecnologia e inovação. 2019. Disponível em:

<https://www.diariodepernambuco.com.br/noticia/vidaurbana/2019/03/rede-municipal-deensino-do-recife-ganha-novo-laboratorio-de-tecnologi.html>. Acesso em: 5 nov. 2019.

DIÁRIO DE PERNAMBUCO. Rede municipal de ensino do Recife ganha quinto laboratório de tecnologia e inovação. 2019. Disponível em:

$<$ https://www.diariodepernambuco.com.br/noticia/vidaurbana/2019/07/rede-municipal-deensino-do-recife-ganha-quinto-laboratorio-de-tecnolo.html>. Acesso em: 5 nov. 2019.

DEPARTMENT OF EDUCATION. Office of Innovation and Improvement. STEM 2026 - A Vision for Innovation in STEM Education. Washington DC: 2016. UNESCO. Current Challenges in Basic Education. Paris: UNESCO, 2009. 
DREIFUS, C. Ideas for Improving Science Education. 2013. Disponível em: $<$ https://archive.nytimes.com/www.nytimes.com/interactive/2013/09/02/science/scienceeducation-voices.html $>$. Acesso em: 3 maio 2018.

JCONLINE. Escolas municipais do recife ganharão laboratórios de ciência e tecnologia. 2018. Disponível em:

<https://jconline.ne10.uol.com.br/canal/cidades/educacao/noticia/2018/12/01/escolasmunicipais-do-recife-ganharao-laboratorios-de-ciencia-e-tecnologia-363955.php $>$. Acesso em: 5 nov. 2019.

GRYNSZPAN , D.; AZEVEDO, S. M . O projeto "abc na educação científica mão na massa" no noroeste fluminense: uma proposta de acompanhamento avaliativo. In: Reunião Anual da SBPC, 58, 2006, Florianópolis. Anais... Florianópolis: SBPC. Disponível em: <http://www.sbpcnet.org.br/livro/58ra/SENIOR/RESUMOS/resumo 3613.html>. Acesso em: 5 nov. 2019.

HIGGINS, S; XIAO, Z; KATSIPATAKI, M. The Impact of Digital Technology on Learning: a Summary for the Education Endowment Foundation. Reino Unido: Durham University, 2012.

LOPES, Renato Matos; FILHO, Moacelio Veranio Silva; ALVES, Neila Guimarães (Org.). Aprendizagem baseada em problema: fundamentos para a aplicação no ensino médio e na formação de professores. Rio de Janeiro: Publiki, 2019. Disponível em:

<https://educapes.capes.gov.br/bitstream/capes/432641/2/APRENDIZAGEM\%20BASEADA\% 20EM\%20PROBLEMAS\%20-

\%20fundamentos\%20para\%20a\%20sua\%20aplica\%C3\%A7\%C3\%A30\%20no\%20Ensino\%20 M\%C3\%A9dio\%20e\%20na\%20Forma\%C3\%A7\%C3\%A3o\%20de\%20Professores.pdf>.

Acesso em: 5 nov. 2019.

MARSH, Jackie et al. Makerspaces in early childhood education: principles of pedagogy and practice. Mind, Culture, and Activity. 2019. https://DOI: 10.1080/10749039.2019.1655651.

MENDES, A. C. S et al. Cinema na escola: caminhos para aprender ciências. In: SIMPOSIO LATINO AMERICANO EN FORMACIÓN DE PROFESORES: TECNOLOGÍA Y EDUCACIÓN, 2016, Valparaiso. Resúmenes I Simposio Latinoamericano en Formación de Profesores: Tecnología y Educación, 2016. p. 137-140.

PERES, P. O que é o STEM: e como ele pode melhorar a sua aula. Revista Nova Escola, 2018. Disponível em https://novaescola.org.br/conteudo/11683/o-que-e-o-stem-e-como-ele-podemelhorar-a-sua-aula. Acesso em: 05 de nov. 2019.

PORTAL DA EDUCAÇÃO. Ciência, Tecnologia e astronomia ao alcance dos alunos da rede municipal. 2019. Disponível em: <http://www.portaldaeducacao.recife.pe.gov.br/groups/ci- 
ncia-tecnologia-e-astronomia-ao-alcance-dos-alunos-da-rede-municipal>. Acesso em: 3 nov. 2019.

SANTOS, M. S. et al. Methodological Innovations Mediated by Technology in Basic Education. In: EUTIC 2016. Network Logic and New Forms of Governance, 2016, Zakynthos/Grécia. EUTIC 2016, p. 196-205.

SILVA, G. S.; PINTO, W. P. A. C. A aprendizagem baseada em problemas por meio de projetos em robótica. In: XLVCOBENGE, 2017, Santa Catarina. Anais... Santa Catarina: Congresso Brasileiro de Educação em Engenharia, 2017. Disponível em:

<https://www.researchgate.net/publication/320430710_A_APRENDIZAGEM_BASEADA_EM _PROBLEMAS_POR_MEIO_DE_PROJETOS_EM_ROBOTICA〉. Acesso em: 5 nov. 2019.

SOUZA, Renata Faria de et. al. Uma Relação entre a metodologia do Projeto "Abc na Educação Cientifica Mão na Massa” e a Teoria de Jean Piaget. In: VIII Enpec, 8, 2011, São Paulo. Anais... São Paulo: Encontro Nacional de Pesquisa em Educação, 2011.

THIBAUT, L et al. Integrated STEM Education: A Systematic Review of Instructional Practices in Secondary Education. European Journal of STEM Education, 2018, 3(1), 02. https://doi.org/10.20897/ejsteme/85525. Disponível em: <https://www.researchgate.net/publication/324878162_Integrated_STEM_Education_A_Syste matic Review of Instructional Practices in Secondary Education>. Acesso em: 5 nov. 2019.

WAKISAKA, M. L. Y; VAZ, A. M. Práticas pedagógicas extraordinárias: análise de virtudes políticas de professores de biologia. In: VIIEnpec, 7, 2009, Santa Catarina. Anais... Santa Catarina: Encontro Nacional de Pesquisa em Educação em Ciências, 2009. Disponível em: <http://posgrad.fae.ufmg.br/posgrad/viienpec/pdfs/441.pdf>. Acesso em: 3 nov. 2019. 